\title{
PENTINGNYA PENGUASAAN APLIKASI MICROSOFT OFFICE UNTUK MENINGKATKAN KEMAMPUAN HARD SKILL MAHASISWA
}

\author{
Desfa Anisa ${ }^{1}$, Retno Kusumo ${ }^{2}$, Natasha ${ }^{3}$ \\ ${ }^{1,2,3}$ Sekolah Tinggi Ilmu Kesehatan Awal Bros Batam, Indonesia \\ E-mail: ${ }^{1)}$ desfaanisa24@gmail.com, ${ }^{2)}$ retnokusumo76@gmail.com
}

\begin{abstract}
Abstrak
Perkembangan teknologi pada saat ini sudah mengalami kemajuan yang sangat pesat khususnya pada software aplikasi yang ada di komputer. Salah satu program aplikasi yang saat ini berkembang seiring dengan teknologi informasi dan komunikasi adalah Microsoft office yang dapat digunakan untuk melakukan pengolahan dokumen dan administrasi. Microsoft Office dirasa perlu diajarkan kepada mahasiswa terkait penggunaan aplikasi tersebut, kususnya aplikasi Microsoft Excel agar dapat meningkatkan kemampuan mahasiswa dalam penggunaan rumus-rumus yang ada di Microsoft Excel. Microsoft Excel merupakan bagian dari Microsoft Office yang sering digunakan untuk pengolahan angka. Metode yang digunakan adalah metode tutorial (pendampingan), tanya jawab dan praktek langsung menggunakan aplikasi. Materi yang disampaikan terdiri dari pengenalan fungsi dan rumus-rumus (formula) yang ada pada Microsoft Excel. Peserta yang mengikuti kegiatan ini berjumlah 12 orang. Kegiatan ini diawali dengan penyampaian materi berupa presentasi (tutorial) dan materi yang disampaikan tersebut langsung dipraktekkan oleh mahasiswa
\end{abstract}

Kata kunci: Tutorial, Aplikasi, Microsoft Excel

\begin{abstract}
The development of technology at this time has progressed very rapidly, especially in application software on computers. One application program that is currently developing along with information and communication technology is Microsoft office which can be used to perform document processing and administration. Microsoft Office is deemed necessary to be taught to students regarding the use of these applications, especially Microsoft Excel applications in order to improve students' abilities in using formulas in Microsoft Excel. Microsoft Excel is part of Microsoft Office which is often used for processing numbers. The method used is the tutorial method (assistance), question and answer and direct practice using the application. The material presented consists of an introduction to functions and formulas in Microsoft Excel. There were 12 participants who took part in this activity. This activity begins with the delivery of material in the form of a presentation (tutorial) and the material presented is immediately practiced by students.
\end{abstract}

Keywords: Tutorial, Application, Microsoft Excel

\section{PENDAHULUAN}

Saat ini perkembangan teknologi sudah mengalami kemajuan yang sangat pesat khususnya pada software aplikasi yang ada di komputer. Salah satu program aplikasi yang saat ini berkembang seiring dengan teknologi informasi dan komunikasi adalah Microsoft office yang dapat digunakan untuk melakukan pengolahan dokumen dan administrasi. Salah 
satu bagian dari Microsoft office adalah Microsoft Word untuk pengolah kata dan Microsoft Excel untuk pengolah angka. Dukungan GUI (Graphic User Interface) pada Microsoft Word dan Microsoft Excel yang sederhana dan interaktif mempermudah user dalam mengoperasikan program aplikasi (Miftakhur Rokhman et al., 2018). Sehingga dari beberapa aplikasi Microsoft Office dirasa perlu diajarkan kepada mahasiswa terkait penggunaan aplikasi tersebut, kususnya aplikasi Microsoft Excel agar dapat meningkatkan kemampuan mahasiswa dalam penggunaan rumus-rumus yang ada di Microsoft Excel.

Komputer untuk saat ini bukan lagi merupakan barang mewah, alat ini sudah banyak digunakan di berbagai bidang pekerjaan seperti halnya pada bidang pendidikan (Riwayadi, 2013). Pada awalnya komputer dimanfaatkan sekolah sebagai penunjang kelancaran pekerjaan pada bidang administrasi dengan memanfaatkan software Microsoft office (Salam \& Ridha, 2019). Nama Microsoft Office bukan lagi sesuatu yang asing bagi kalangan mahasiswa karena hampir setiap hari aplikasi tersebut sudah sering digunakan, mulai dari membuat tugas makalah, membuat laporan karya tulis ilmiah dan lain sebagainya. Microsoft Office merupakan sebutan untuk paket aplikasi perkantoran yang dibuat oleh Microsoft dan dirancang untuk dijalankan pada sistem operasi windows (Noviandri \& Sarwandi, 2017).

Microsoft Excel merupakan sebuah program aplikasi lembar kerja spreadsheet yang dibuat dan didistribusikan oleh Microsoft Corporation untuk sistem operasi Microsoft Windows dan Mac OS. Aplikasi ini memiliki fitur kalkulasi dan pembuatan grafik dengan menggunakan strategi marketing. Microsoft yang agresif, menjadikan Microsoft Excel sebagai salah satu program komputer yang populer digunakan di dalam komputer mikro. Bahkan, saat ini program ini merupakan program spreadsheet paling banyak digunakan oleh banyak pihak, baik di platform PC berbasis Windows maupun platform Macintosh berbasis Mac OS, semenjak versi 5.0 diterbitkan pada tahun 1993. Aplikasi ini merupakan bagian dari Microsoft Office System, dan versi terakhir adalah versi Excel 2013 yang diintegrasikan di dalam paket Microsoft Office 2013 (Miftakhur Rokhman et al., 2018).

Microsoft Excel menawarkan banyak keunggulan antar muka jika dibandingkan dengan program spread sheet sebelumnya, tapi esensinya masih sama dengan VisiCalc (perangkat lunak spread sheet yang terkenal pertama kali). Sel disusun dalam baris dan kolom, serta mengandung data atau formula yang berisi referensi absolut atau referensi relatif terhadap sel lainnya. Microsoft Excel juga menawarkan penghitungan kembali terhadap sel-sel secara cerdas, di mana hanya sel yang berkaitan dengan sel tersebut saja yang akan diperbarui nilanya (di mana program-program spread sheet lainnya menghitung ulang keseluruhan data atau menunggu perintah khusus dari pengguna). Selain itu, Microsoft Excel juga menawarkan fitur pengolahan grafik yang sangat baik (Suryati et al., 2020).

\section{METODE PENELITIAN}

Kegiatan ini dilakukan pada tanggal 17 Januari 2022 dengan jumlah peserta sebanyak 12 orang. Untuk memberikan pengetahuan dan pemahaman mengenai penggunaan aplikasi Microsoft Excel maka kegiatan ini dilakukan dengan menggunakan metode tutorial (pendampingan), diskusi, tanya jawab dan praktek langsung penggunaan aplikasi Microsoft Excel di laptop masing-masing peserta. Hal ini bertujuan agar peserta dapat memahami materi yang disampaikan, sehingga dapat diimplementasikan secara aplikatif dan membekali peserta untuk memiliki kemampuan mengoperasikan aplikasi Microsoft Excel. 


\section{PORTAL RISET DAN INOVASI PENGABDIAN MASYARAKAT (PRIMA) \\ VOLUME 1 ISSUE 1 (2022)}

\section{HASIL DAN PEMBAHASAN}

Hasil dari kegiatan ini adalah meningkatnya pengetahuan serta kemahiran mahasiswa dalam menggunakan aplikasi Microsoft Excel. Pada kegiatan ini peserta dilatih untuk memiliki kemampuan mengoperasikan aplikasi Microsoft Excel.

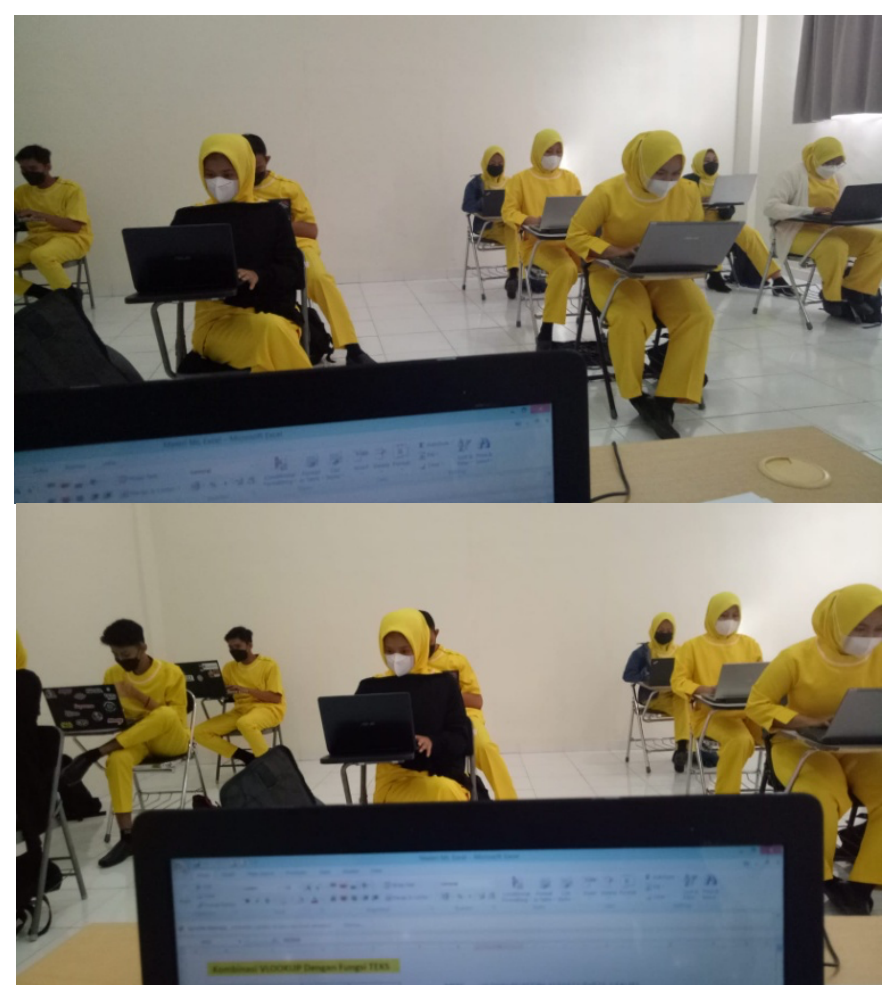

Gambar 1 Peserta Kegiatan

Gambar 1 memperlihatkan suasana kegiatan yang terjadi saat menggunakan aplikasi Microsoft Excel. Penulis sudah memberikan materi terkait aplikasi Microsoft Excel kepada peserta. Kegiatan ini berlangsung pada tanggal 17 Januari 2022 yang diikuti sebanyak 12 peserta. Selama kegiatan berlangsung para peserta tampak sangat antusias dan keingintahuannya begitu tinggi dengan materi yang diajarkan. Peserta memperoleh banyak manfaat dan keuntungan dari kegiatan yang dilaksanakan. Materi yang diberikan terdiri dari pengenalan fungsi dan rumus-rumus (formula) yang ada pada Microsoft Excel seperti penggunaan Sum, Max, Min, Average, If, Left, Mid, Right, Vlookup Dan Hlookup. Setelah pemberian materi dilakukan dengan metode tutorial (pendampingan), untuk menguji pemahaman dan pengetahuan peserta terkait materi yang disampaikan dalam mengoperasikan aplikasi Microsoft Excel maka pada akhir kegiatan dilakukan post test. Pelaksanaan post test pada peserta dapat dilihat pada Gambar 2 berikut. 


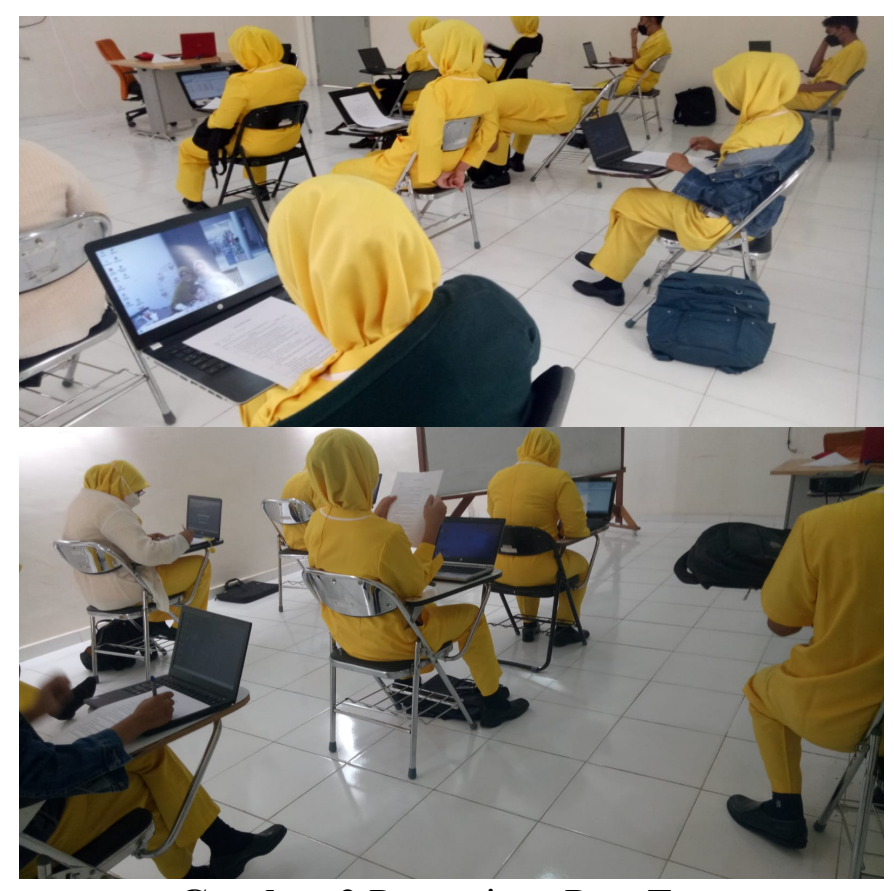

Gambar 2 Pengerjaan Post Test

\section{KESIMPULAN}

Kegiatan ini sudah dapat terlaksana dengan baik sesuai dengan rencana yang ditetapkan. Selama kegiatan berlangsung menunjukan adanya peningkatan pemahaman dan keterampilan dari beberapa peserta dalam mengoperasikan penggunaan rumus-rumus (formula) yang ada pada aplikasi Microsoft Excel.

\section{DAFTAR PUSTAKA}

Miftakhur Rokhman, M., Adi Wibowo, S., Agus Pranoto, Y., \& Ardi Widodo, K. (2018). Pelatihan Pemanfaatan Microsoft Office Pada Staf Pengajar Di SMPLBN (Sekolah Menengah Pertama Luar Biasa Negeri) Kota Malang. Jurnal Mnemonic, 1(1), 4-9.

Noviandri, H., \& Sarwandi. (2017). Microsoft Office 2016 untuk Pemula. Elex Media Komputindo.

Riwayadi, P. (2013). Pemanfaatan Perkembangan Teknologi Informasi Dan Komunikasi Untuk Kemajuan Pendidikan Di Indonesia. available at PLS-UM Database.

Salam, A., \& Ridha, R. (2019). Sistem Basis Data dengan Microsoft Office Access : Teori dan Praktikum. KITA Publisher.

Suryati, K., Putri, N. W. S., \& Krisna, E. D. (2020). Pelatihan Microsoft Excel dalam Pembelajaran Matematika. 2(2), 40-48. 